\title{
Effectiveness of a small marine reserve in southern California
}

\author{
P. Ed Parnell ${ }^{1}$, Cleridy E. Lennert-Cody ${ }^{2}$, Leen Geelen ${ }^{3}$, Laura D. Stanley ${ }^{4}$, \\ Paul K. Dayton ${ }^{1}$
}

\author{
${ }^{1}$ Scripps Institution of Oceanography, Integrative Oceanography Division, University of California, San Diego, \\ La Jolla, California 92093-0227, USA \\ ${ }^{2}$ Inter-American Tropical Tuna Commission, 8604 La Jolla Shores Drive, La Jolla, California 92037-1508, USA \\ ${ }^{3} 67$ bis Rue du Point du Jour, 92100 Boulogne-Billancourt, France \\ ${ }^{4}$ UCSD Civic Collaborative, University of California, San Diego, La Jolla, California 92093-0176P, USA
}

\begin{abstract}
While relatively small, the San Diego-La Jolla Ecological Reserve is one of the oldest in California, and it contains giant-kelp-forest, boulder-reef, submarine-canyon and sandy-shelf habitats. We evaluated the effectiveness of this 'no-take' marine reserve and gauged its success according to the goals implicit in its design. To overcome the lack of data prior to its establishment, we employed habitat-specific analyses. Our study comprised 4 components: (1) an historical review of its establishment; (2) a survey of conspicuous species in kelp-forest, submarine-canyon, and boulderreef habitats; (3) comparisons with historical data; (4) a public survey regarding awareness, knowledge, and support of the reserve. Despite $30 \mathrm{yr}$ of protection, only a few sessile or residential species exhibit positive effects of protection, and most fished species have decreased in abundance inside the reserve. However, the reserve protects the largest remaining populations of green abalone Haliotis fulgens and vermillion rockfish Sebastes miniatus in the area, which therefore represent important sources of larvae. Implementation and enforcement of coastal reserves depends on public support, but the results of the public survey indicated a lack of knowledge of the reserve, highlighting the need for improved public education in this respect. The results of the study reflect the limited value of small reserves and document the inadequacy of inside/outside comparisons as tests of reserve effectiveness when baseline and historical data are lacking.
\end{abstract}

KEY WORDS: Marine protected area $\cdot$ Reserves $\cdot$ Kelp $\cdot$ Abalone $\cdot$ Urchins $\cdot$ Submarine-canyon Rockfish · Public opinion

- Resale or republication not permitted without written consent of the publisher

\section{INTRODUCTION}

\section{Conservation and enhancive reserves}

Coastal zones are managed with the objectives of conserving biodiversity and intrinsic ecosystem services and sustainable fisheries. Marine parks or fully protected marine reserves offer benchmarks and protect ecosystem integrity, while encouraging the aesthetic appreciation of nature, education, and research. These objectives define the concept of conservation reserves, which differ from reserves intended as tools to enhance marine resources ('enhancive reserves') (Bohnsack 1998, Dayton et al. 2000).

For conservation reserves to be successful, they must be large enough to enable most important populations to be self-sustaining (Halpern \& Warner 2003). Enhancive reserves, in contrast, must be large enough to supply fished areas with adults and juveniles via spillover (Russ \& Alcala 1996) and larvae (Tremblay et al. 1994). The 2 types of reserves are not mutually exclusive, but it is generally thought that enhancive reserves must be larger than conservation reserves to be effective (Halpern \& Warner 2003). 
For a reserve to be self-sustaining for a particular species, it must be large enough to (1) encompass the ambits of a sufficient number of adults and juveniles and thus prevent their exposure to fishing, and (2) ensure adequate larval retention to prevent recruitment limitation. Therefore, the ideal size of a conservation reserve varies among species but, in general, should be large enough to self-sustain important fished species representative of the protected habitat (Dayton et al. 2000, Halpern \& Warner 2003). Most research on small coastal reserves focuses on a few species that $a$ priori appear likely to be protected by the reserve and on resource-enhancement rather than self-sustainment aspects.

The San Diego-La Jolla Ecological Reserve (SDLJER), established in 1971, is one of the oldest 'no-take' reserves in southern California and was implicitly established as a conservation reserve. In an effort to gauge its success, we have evaluated whether it is selfsustaining and if it has achieved the goals set forth in its design, and we have also examined the factors affecting its success. We present a synthesis of the factors that guided its establishment, comparisons of intensive surveys both within and outside its boundaries, comparisons of present and historical densities, and an evaluation of public support for, and knowledge of, the reserve as factors affecting its success. Finally, we also consider the long-term effectiveness of the reserve as a model of the value of small reserves in temperate waters.

\section{San Diego-La Jolla Ecological Reserve}

No biological data are available from the period prior to the establishment of the SDLJER. However, it is obvious from historical photos (e.g. Kuhn 1984), archived notes of late Scripps researchers (W. North, C. Limbaugh, C. Hubbs), and interviews of living researchers (J. Stewart, R. McConnaghey, J. Quast) that there had been substantial anthropogenic changes in the area prior to the establishment of the reserve, including overfishing and coastal development.

Depletion of giant seabass Stereolepis gigas, broomtail grouper Mycteroperca xenarcha and green abalone Haliotis fulgens in southern La Jolla Bay, where the present reserve is located (see Fig. 1), and offshore from Point La Jolla was noticed by Scripps researchers (C. Limbaugh, J. Stewart, R. Dill) as early as the late 1940s and led to repeated calls for the development of a marine reserve. Later, Scripps researchers observed significant damage to the canyon-rim habitat of the La Jolla submarine canyon by squid trawlers, leading to renewed calls for the development of a marine reserve to protect this important fish nursery habitat. All efforts to establish a reserve were successfully rebuffed by fishing interests until 1971 when a 'notake' marine reserve was established by the City of San Diego in cooperation with the California Department of Fish and Game. The mandated goals of the SDLJER were ' ... to protect threatened or endangered native plants, wildlife, or aquatic organisms or specialized habitat types...' (from McArdle 1997). Therefore, the mandated goals of the reserve were ultimately much more general than the considerations leading to its establishment. As part of our evaluation of the reserve we set out to gauge (1) its success based on these goals, specifically the implicit goals mentioned above that eventually led to its establishment, and (2) its effectiveness as a conservation reserve.

\section{MATERIALS AND METHODS}

Site description. The SDLJER protects $\sim 2.16 \mathrm{~km}^{2}$ of the waters offshore of La Jolla shores and La Jolla cove (Fig. 1). The median size of $\sim 1300$ marine reserves (reviewed by McClanahan 1999) is $\sim 16 \mathrm{~km}^{2}$; therefore, the SDLJER is relatively small. In addition to being small, evaluation of the reserve is complicated because it contains 4 different subtidal habitats: (1) a subtidal boulder-reef habitat from La Jolla cove to Devil's Slide; (2) the northern margin of the La Jolla kelp forest $\left(\sim 0.10 \mathrm{~km}^{2}\right.$ of the $\sim 8.25 \mathrm{~km}^{2}$ total area of the La Jolla kelp forest); (3) the La Jolla branch of the La Jolla submarine canyon, which has steep sandstone cliffs and promontories at depths of $\sim 20$ to $130 \mathrm{~m}$ within the Reserve; (4) a broad, gently sloping, sandy shelf north of the submarine canyon. We studied the boulder-reef, kelp-forest and submarine-canyon habitats because they were initially targeted for protection within the reserve, and density estimates for species inhabiting the boulder-reef and kelp-forest habitats were available from 1979 for comparison.

Inside/outside comparisons. Kelp habitats: Since baseline ('before') data were not available for a proper BACI (before, after, control, impact) analysis (e.g. Underwood 1992), we conducted inside/outside comparisons among similar microhabitats that were discriminated quantitatively. This ensured that inside/outside comparisons were conducted between similar habitats, increasing the likelihood that differences were due to protection. An important caveat is that this approach does not control for temporal changes in habitat. This is probably less of a problem for mobile species that can respond to changes in habitat via redistribution than for sessile species that can only redistribute over generations and therefore exhibit delayed responses to habitat change. 
Extensive surveys of physical habitat, algae, fishes, and invertebrates were conducted within the kelp forest both inside and outside the reserve. The entire La Jolla kelp forest was divided into squares of $250 \mathrm{~m}$ on each side; surveys were conducted using band transects $(30 \times 4 \mathrm{~m})$ placed randomly within a grid. At least 2 transects were conducted within each square. Habitat parameters included depth measurements and estimates of sharp vertical relief within $1 \mathrm{~m}$ of the transect line at every $1 \mathrm{~m}$ interval mark, substrate type (sand, bedrock, rock, cobble), and algae every $0.5 \mathrm{~m}$ interval mark, and the presence/absence of major benthic features (ledges, crevices, overhangs) along $5 \mathrm{~m}$ sections.
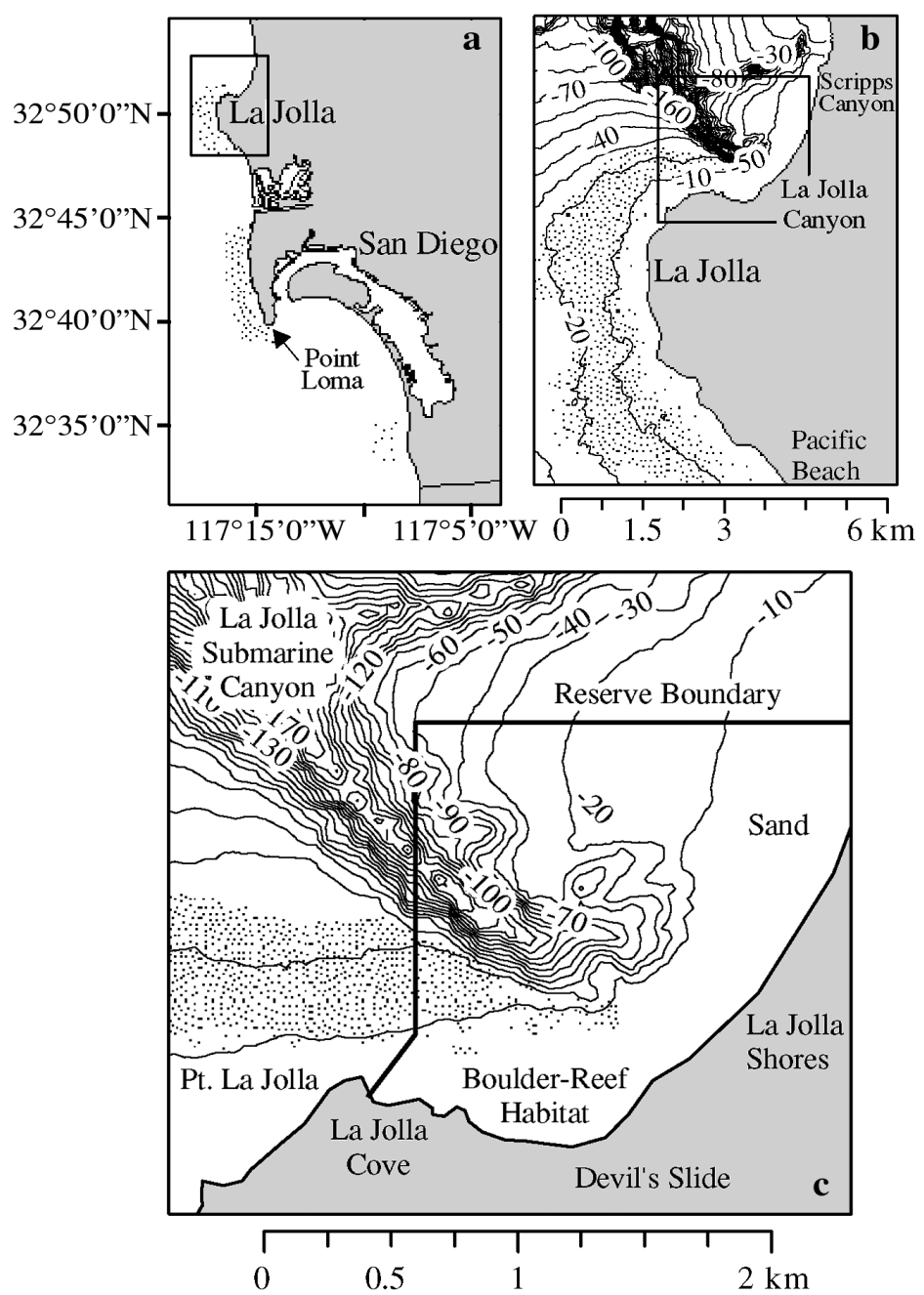

Fig. 1. (a) San Diego area, showing locations of La Jolla and Point Loma kelp forest; inset = area magnified in upper right graph. (b) La Jolla kelp forest and San Diego La Jolla Ecological Reserve, showing the 2 branches of the La Jolla submarine canyon; inset = area magnified in bottom graph. (c) Map of reserve indicating locations of kelp forest, canyon head within reserve, and boulder-reef habitat. Depth contour (m) are shown; stippling: kelp canopy
We counted 33 species of invertebrates and 27 species of fish in the band transects. Of these, only the species currently or historically targeted for commercial or recreational harvest were included in the inside/outside analysis of densities. Sizes (total length, TL) of the kelp bass Paralabrax clathratus, barred sand bass $P$. nebulifer and male and female sheephead Semicossyphus pulcher were estimated visually at a resolution of $5 \mathrm{~cm}$ using a plastic slate as a reference. Inter-diver comparisons showed this resolution to be most appropriate.

Substratum and algal data were analyzed using hierarchical divisive clustering (Kaufman \& Rousseeuw 1990) to characterize habitat types within the La Jolla kelp forest, both inside and outside the reserve. Substratum variables used in the cluster analysis were percent cover of pavement, cobble, rock, and sand, average bottom relief, and presence/absence of 1 or more major benthic features. Algal variables used in the cluster analysis included density of giant kelp Macrocystis pyrifera and other brown algae including Pterygophora californica, Laminaria farlowii, Cystoseira osmundacea, Desmerestia spp., red turf algae, and articulated coralline algae, and presence/absence of the kelps Egregia menziesii, Eisenia arborea, brown turf and crustose coralline algae species. The dissimilarity matrix was constructed based on Euclidean distance for the percent cover and density data, and on the Jaccard coefficient for the presence/absence data.

The robustness of the cluster analysis results was examined by applying the clustering technique to simulated data. We generated 1000 simulated data sets by sampling with replacement from reserve and nonreserve transects to match original sample sizes. Results of cluster analyses on simulated data were compared to those of the cluster analysis of the original data, beginning at the first main split of the data and working downwards. At a given level in the dendograms, each cluster of the simulated data was compared to that of the original data by counting the number of transects in common. The minimum percentage of transects in common between observed and simulated clusters was taken as a measure of agreement. Levels in the dendogram containing 2, 3, 5, 7, 8 and 10 clusters were tested. The median minimum percentage of transects in common was used to summarize the results of the 1000 comparisons at each level.

Statistical comparisons of fish and invertebrate densities inside and outside the reserve were then conducted among transects within the same habitat cluster using the non-parametric Mann-Whitney $U$-test. The cluster analysis identified transects with comparable habitats both within and outside the reserve that could be used for statistical comparisons. Comparisons among different habitats are not appropriate, since species have different affinities among habitats. The 
truncated product method (TPM; Zaykin et al. 2002) a method that is intermediate between the extremes of no correction for multiple comparisons and the sequential Bonferroni adjustment (Holm 1979), as advocated by Neuhäuser (2004) — was applied to the pvalues resulting from the Mann-Whitney comparisons.

Densities of large male ( $>50 \mathrm{~cm}$ TL) and female ( $>25 \mathrm{~cm}$ TL) sheephead inside the reserve were compared to those outside within the same habitat cluster using randomization tests (Manly 1991). A randomization distribution of the difference in densities was constructed by generating 4999 estimates of densities inside and outside the reserve from repeated random assignment of transects to 2 groups (inside vs. outside). To test the null hypothesis of no reserve effect, the proportion of differences in density that were as large or larger than those observed was computed from the randomization distribution.

Areas found to have high densities of sea urchins both inside and outside the reserve were revisited to obtain the size-frequencies of urchins for inside/outside comparisons of urchin sizes. The 2 most abundant urchins, the purple urchin Strongylocentrotus purpuratus (which is not fished) and the red urchin $S$. franciscanus (which is the target of a major fishery in California) were measured using calipers. Sampling was conducted within haphazardly placed $1 \mathrm{~m}^{2}$ quadrats. Urchins were collected exhaustively from the quadrats and brought to the surface for measurement.

Sea urchin size data from inside and outside the reserve were summarized by smoothed size-frequency distributions constructed with a kernel-density estimator (Gaussian kernel; Silverman 1986). Bandwidths were selected separately for each species and location using biased cross-validation (Venables \& Ripley 1999). Large modal sizes inside and outside the reserve were compared using a bootstrap test (Efron \& Tibshirani 1993) of the null hypothesis that the distributions inside and outside the reserve were the same within species. Bootstrap samples were obtained by resampling with replacement from the pooled inside and outside measurements. Bootstrap estimates of large modal size were obtained by smoothing the bootstrap samples of size data as described above. Distributions of differences in large modal size were constructed from 1000 bootstrap samples. The observed modal differences for red and purple urchins were then compared to their bootstrap difference distributions. Approximate confidence intervals for the large modal size were obtained using the percentile method (Efron \& Tibshirani 1993).

Boulder-reef habitat: Green abalone Haliotis fulgens were specifically targeted for protection in the reserve. All harvest of green abalone was closed throughout California in 1998 because of drastically reduced populations. Because of the closure, the reserve is presently less relevant for this species than for other species that are still fished. However, we assumed that the effects of protection such as higher densities, larger sizes, and larger spawning aggregations would persist for several years. Therefore, we conducted surveys throughout the La Jolla area to determine how effective the reserve has been for green abalone abundance.

Typically, green abalone occur at depths shallower than giant kelp, so separate surveys for green abalone were conducted in addition to the kelp forest surveys. Green abalone habitat was first determined from georeferenced aerial photographs (Ocean Imaging, Solana Beach, California). Bathymetric contours (generated using National Geophysical Data Center, NOAA data) were then overlaid onto the photos using Surfer (software). Areas that were rocky and shallower than $6 \mathrm{~m}$ were surveyed for green abalone using a stratified random sampling technique. The coastline was divided into segments (500 m long) and beginning points for surveys were generated randomly; 2 SCUBA divers, accompanied by a snorkeler with a GPS at the surface, searched for green abalone in appropriate habitat, beginning at the random coordinates. The swim track was internally recorded by the GPS at $5 \mathrm{~s}$ intervals and the divers' watches were calibrated to the GPS. Divers searched in parallel bands while staying within sight of one another (typically 3 to $5 \mathrm{~m}$ ). Divers noted habitats, the times abalone were sighted, size, and occurrence in aggregations. Densities were then calculated by dividing the number of abalone by the area searched within each GPS transect. Estimates of abalone populations in each segment were calculated using the area of rocky habitat between the $6 \mathrm{~m}$ contour and shore. Surveys were conducted from spring to fall of 2003.

Sizes of abalone inside and outside the reserve were compared to determine if abalone were larger inside the reserve prior to the closure. Legal size at the time of closure was $15.2 \mathrm{~cm}$. Application of the von Bertalanffy growth function $K$, based on $K=0.101$ (Tutschulte \& Connell 1988) and $25 \mathrm{~cm}$ for length $L_{\infty}$ (largest green abalone observed in this study), indicates that abalones that were of legal harvesting size in 1998 would be $\geq 18 \mathrm{~cm} 5$ yr later, when we conducted our survey. Therefore, the density of abalone $\geq 18 \mathrm{~cm}$ inside and outside the reserve were compared using a randomization test based on 4999 simulated data sets. The densities of abalone aggregations were also compared inside and outside the reserve using a randomization test.

Submarine canyons: In northern La Jolla, 2 branches of the La Jolla submarine canyon encroach within $100 \mathrm{~m}$ of shore (Fig. 1). The southern branch, the La Jolla Canyon, is fully protected within the SDLJER. 
The head of the northern branch, Scripps Canyon, is located approximately $2 \mathrm{~km}$ north of the La Jolla branch and is not protected. The proximity and similarity of these 2 canyons enabled comparisons of fish populations between a protected canyon and those of a similar but unprotected canyon to determine if the reserve has been effective with regard to fishes in canyon habitats.

Surveys were conducted using a SeaBotix LBV150 remotely operated vehicle (ROV) at depths of 50 to $125 \mathrm{~m}$, deployed from a small boat. High-resolution bathymetric data ( $2 \mathrm{~m}$ horizontal resolution) of the canyon heads was used to generate bathymetric charts of the canyons to locate areas having similar habitat. Ridges and outcrops in areas with steep bathymetry were targeted since many species of fishes cohabit these areas in the canyon heads (P. E. Parnell pers. obs.). The surveys consisted of ROV video-transects in which the boat was anchored at a predetermined coordinate chosen using the high-resolution bathymetric maps and target depth. The ROV was 'flown' down the anchor line to the bottom, where it began horizontal video-transect surveys while remaining at a constant depth. At the end of each transect, the ROV was flown rapidly to the surface using its vertical thruster, and its coordinates were determined immediately using a differential GPS. The length of each transect was determined by measuring the pathlength along the contour from beginning to endpoints. Pathlengths were used to standardize fish counts along ROV transects. Transects were only included in the analysis if they were conducted near ridges and outcrops. Surveys were conducted from late spring to early fall 2003. Relative abundances for both Sebastes miniatus and Semicissyphus pulcher were compared among canyons using Mann-Whitney tests, and post-hoc power analysis was done using GPower (available at www.psycho. uni-duesseldorf.de/aap/projects/gpower/index.html).

Historical data. Abundance data for invertebrates estimated from band transect data from this study were compared with abundance estimates from Kobayashi (1979). The abundance estimates of Kobayashi (1979) were from data collected along band transects $(25 \times$ $2 \mathrm{~m}$ ) with counts of organisms made every $5 \mathrm{~m}$ along the line, and were grouped by habitat type. Density estimates of several species of invertebrates were made by Kobayashi (1979), but were presented only as means (variability and sample sizes were not given). Since the raw data were no longer available, comparisons of the earlier data with data from this study could only be made by checking if the means from 1979 fell within the $95 \%$ confidence limits of mean abundances from this study.

Public survey. Because meaningful implementation and enforcement of coastal reserves in heavily urban- ized areas depends on public support, a survey of different ocean-user groups and the general public was conducted to gauge attitudes, knowledge, and perceptions of marine reserves in general and the SDLJER in particular. Public awareness of the rules and boundaries of the reserve are an important component of enforcement. Only residents of San Diego County were surveyed because the survey was designed to test local knowledge of the reserve. Participants were selected randomly and were stratified by population groups: divers, fishers, kayakers, beach-goers, and the general public. Participants were assigned to usergroups based on their most frequent ocean activity, and were targeted at areas where they are known to aggregate (e.g. fishing-tackle stores, dive shops and beaches). The general public was questioned randomly throughout the county.

\section{RESULTS}

\section{Kelp habitat}

A total of 286 transects were conducted during the spring and summer of 2002; 16 of these were conducted within the single grid box located in the kelp habitat within the reserve. Results of the cluster analysis suggest that the reserve is dominated by 1 habitat type. Of the 13 transects within the reserve that were fully sampled, 11 were in the same cluster (Fig. 2); 58 transects conducted outside the reserve clustered in this same habitat. This 'reserve' cluster was identified at the first split of the data and was robust to sampling variability. The median minimum percent of transects in common between simulated and original clusters at the first split of the data was $98 \%$, with $86 \%$ at the second split and $57 \%$ at the third split.

The kelp habitat in the reserve was characterized by reefs (features extending at least $1 \mathrm{~m}$ above-bottom with an area $>1 \mathrm{~m}^{2}$ ), sharp vertical relief, crevices and overhangs, and moderate levels (relative to the other clusters) of sand. The algal species that distinguished this habitat from other areas within the kelp bed were Egregia menziesii, Eisenia arborea, Cystoseira osmundacea and Desmerestia spp., and turf-forming red algae (foliose articulate coralline species).

Inside/outside comparisons. Inside/outside comparisons were only possible for 7 species of targeted animals (Table 1). These comprised kelp bass, barred sand bass, male and female sheephead, red urchins, legal-sized spiny lobster Panulirus interruptus, the rock scallop Crassedoma giganteum, and the pink abalone Haliotis corrugata. There were not enough individuals of other targeted species to conduct statistical comparisons. The results indicate that individual 
species' comparisons were significant $(\alpha=0.05)$ for red urchins, rock scallops, and male and female sheephead, whose densities were all higher in the reserve. The summary $p$-value from the truncated product

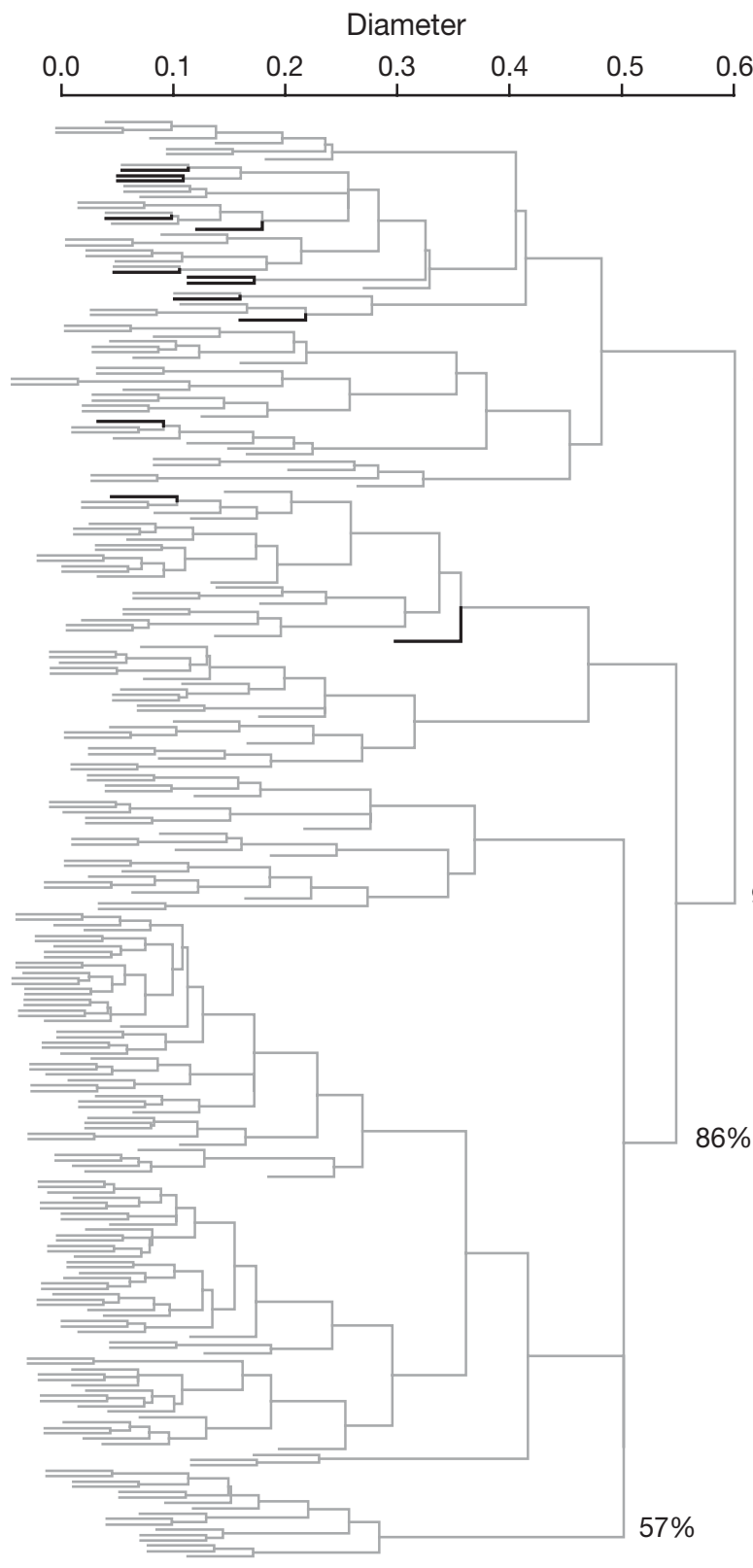

Fig. 2. Results of habitat analysis using hierarchical divisive clustering. Each terminal branch on left represents one $30 \mathrm{~m}$ transect; bold-face branches: transects conducted within reserve. Diameter of a cluster is the largest dissimilarity between transects within that cluster. Percentages on right: median minimum similiarity between clusters obtained from simulated data and clusters obtained from original data for first major splits of data (see 'Materials and methods' for details) method was $0.00025(\alpha, \tau=0.05)$, suggesting that the joint null hypothesis of no reserve effect for any of the species can be rejected and that, accounting for multiple comparisons, there is indeed a significant $(\alpha=0.05)$ reserve effect for at least 1 of these 3 species.

Fish size. Size frequencies of kelp bass were similar inside and outside the reserve. However, the sizefrequency distributions of male and female sheephead inside and outside the reserve differed (Fig. 3). A significantly (achieved significance level, ASL $=0.046$ ) larger proportion of males $>50 \mathrm{~cm}$ were observed inside the reserve. A larger but non-significant $(\mathrm{ASL}=0.350)$ proportion of females $>25 \mathrm{~cm}$ were also observed in the reserve (Fig. 3). Too few barred sand

$\begin{array}{ll}\text { Reserve } & \text { bass were observed for size comparisons. } \\ \text { group } & \text { Sea urchin size. Smoothed size-frequency distribu- }\end{array}$ tions of red and purple urchins show differences that probably reflect fishing pressure on red urchins outside the reserve (Fig. 4). The observed difference between the modes of red urchins inside and outside the reserve was $17 \mathrm{~mm}$ and the distributions (as summarized by the large modal size) were significantly different (ASL $\ll 0.001$ ). The observed difference for purple urchins was $1 \mathrm{~mm}$ and was not significant $(\mathrm{ASL}=0.71)$. Approximate $95 \%$ confidence intervals (lower and upper boundaries) for the large modal size for red urchins were 96 and $109 \mathrm{~mm}$ and 85 and $93 \mathrm{~mm}$ inside and outside the reserve, respectively. Therefore, the population of adult red urchins was significantly larger inside the reserve.
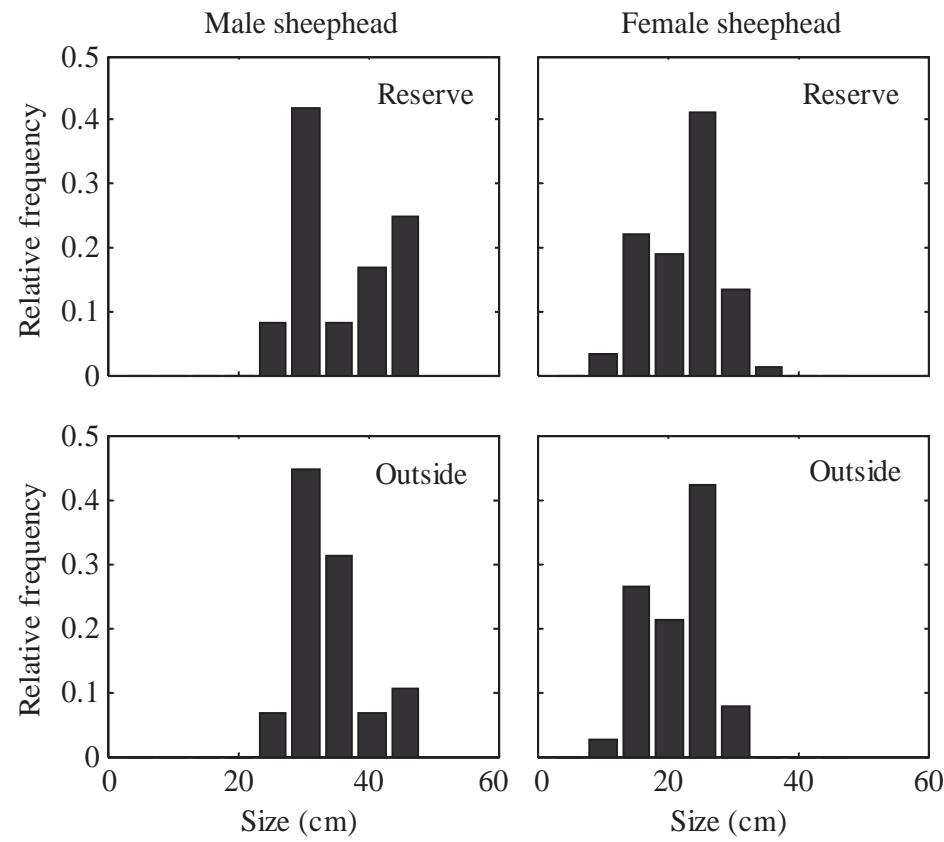

Fig. 3. Semicossyphus pulcher. Size-frequency distributions of male and female sheephead inside and outside reserve in similar habitats 

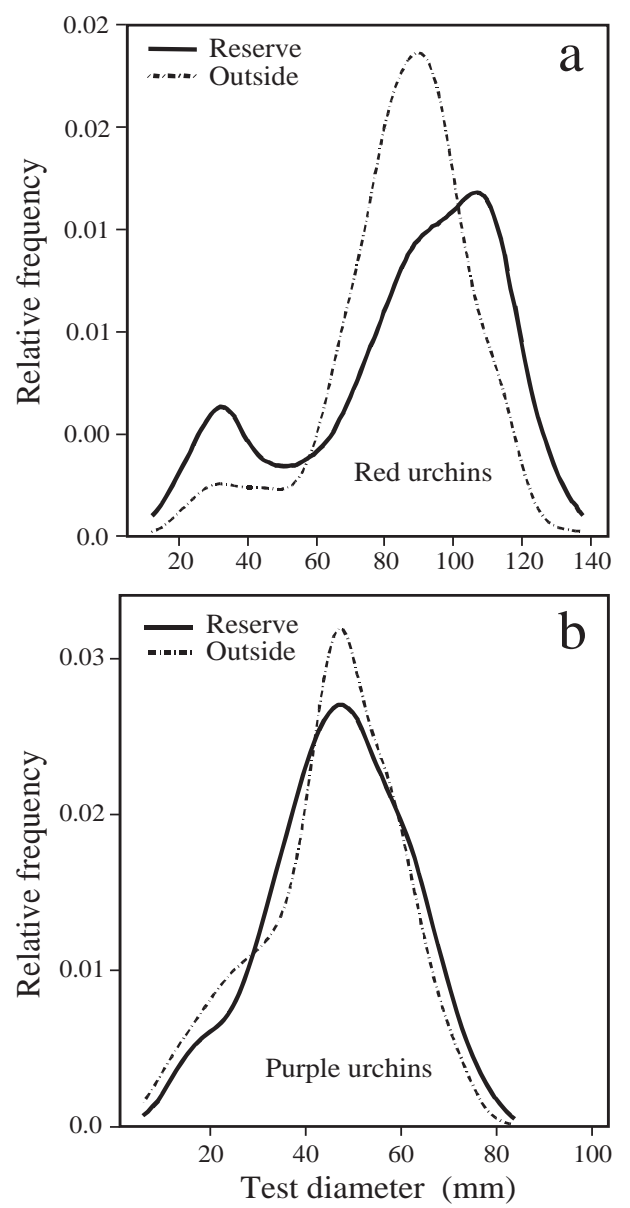

Fig. 4. (a) Strongylocentrotus franciscanus and (b) S. purpuratus. Size-frequency distributions of populations inside and outside reserve

\section{Green abalones in boulder-reef habitat}

The analysis of suitable habitat for green abalone yielded a total estimate of $\sim 1.34 \mathrm{~km}^{2}$ throughout the La Jolla area $\left(\sim 0.15\right.$ and $\sim 1.18 \mathrm{~km}^{2}$ inside and outside the SDLJER, respectively). The GPS transects covered approximately $4 \%$ of all green abalone habitat. Densities of abalone were significantly greater (Mann-Whitney $U$-test, $\mathrm{p}=0.001$ ) inside the reserve $\left(\right.$ mean $=0.0073 \mathrm{~m}^{-2}, \mathrm{SE}=$ 0.0021 ) than outside (mean $=0.0008$ $\mathrm{m}^{-2}, \mathrm{SE}=0.0002$ ). A significant reserve effect was also found for the density of large ( $\geq 18 \mathrm{~cm}$ ) abalone (Fig. 5; $\mathrm{ASL}=0.0006)$, with the average density of large green abalone within the reserve larger by a factor of $\sim 2$. Green abalones were also significantly more likely to be found in aggregations inside

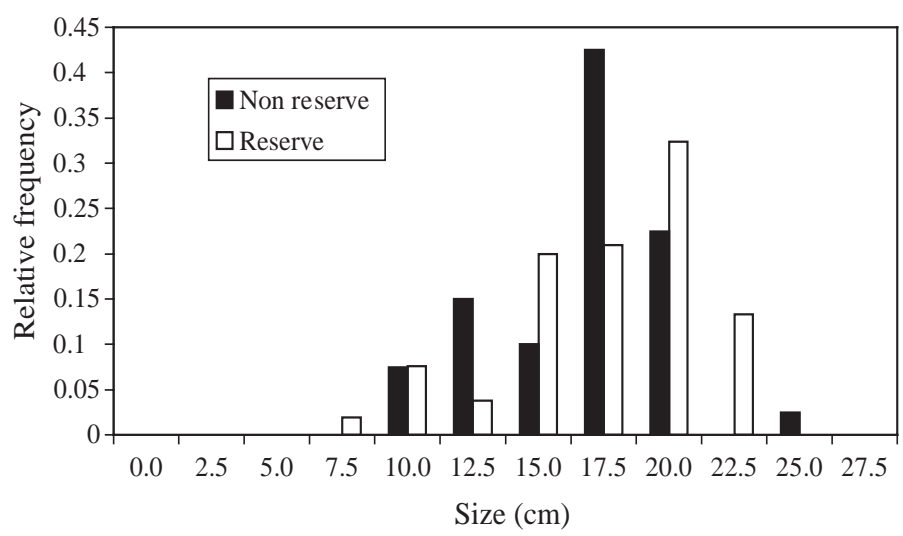

Fig. 5. Haliotis fulgens. Size-frequency distributions inside and outside reserve in boulder-reef habitat

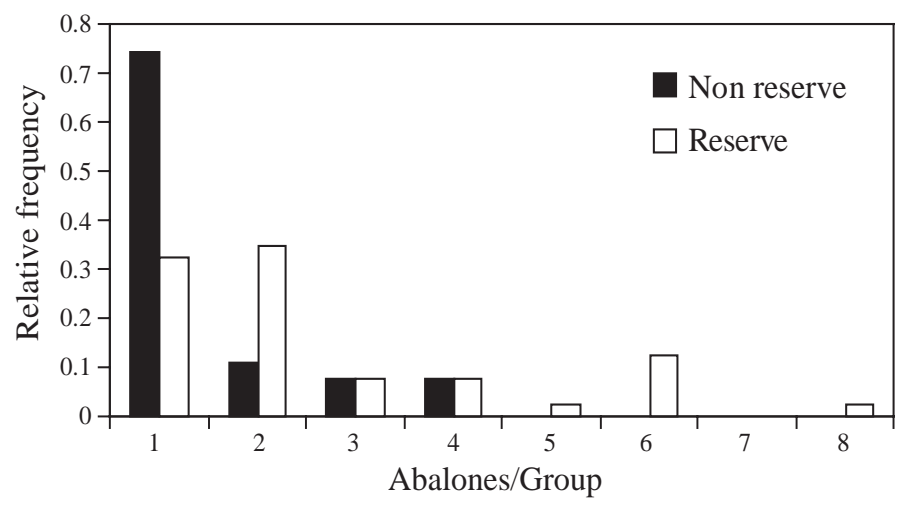

Fig. 6. Haliotis fulgens . Frequency-distribution of individuals and aggregations (combined data) inside and outside reserve in boulder-reef habitat

the reserve (Fig. 6; ASL $=0.001$ ). Less than $25 \%$ of abalone outside the reserve were in aggregations, while $\sim 68 \%$ of abalone inside the reserve were in aggregations. Further, the aggregations inside the reserve were all composed of large individuals $(\geq 18 \mathrm{~cm})$. An estimate

Table 1. Mean (SE) densities and results of inside/outside comparisons of harvested fishes and invertebrates. Probabilities (Mann-Whitney $U$-tests) are shown

\begin{tabular}{|c|c|c|c|}
\hline Species & Inside & Outside & $\mathrm{p}$ \\
\hline \multicolumn{4}{|l|}{ Invertebrates $\left(\mathrm{m}^{-2}\right)$} \\
\hline Strongylocentrotus franciscanus & $0.855(0.152)$ & $0.0218(0.038)$ & $<0.0001$ \\
\hline Haliotis corrugata & $0.0025(0.0014)$ & $0.0038(0.0010)$ & 0.9068 \\
\hline Panuliris interruptis (legal size) & $0.0059(0.0016)$ & $0.0037(0.0007)$ & 0.0655 \\
\hline Crassadoma giganteum & $0.0057(0.0025)$ & $0.0014(0.0006)$ & 0.0151 \\
\hline \multicolumn{4}{|l|}{ Fishes $\left(100 \mathrm{~m}^{-2}\right)$} \\
\hline Paralabrax clathratus & $2.948(0.817)$ & $3.065(0.612)$ & 0.9191 \\
\hline Paralabrax nebulifer & $1.448(0.124)$ & $1.97(0.441)$ & 0.1663 \\
\hline Semicossyphus pulcher (male) & $0.768(0.117)$ & $0.447(0.065)$ & 0.0421 \\
\hline Semicossyphus pulcher (female) & $2.435(0.390)$ & $1.373(0.158)$ & 0.0450 \\
\hline
\end{tabular}


of the number of green abalone remaining in the La Jolla area was calculated as the product of the average densities in each sector divided by the area of each sector (Fig. 7). This yielded an estimate of 1936 green abalone (95\% confidence limit range of 310 to 3111) remaining throughout the La Jolla area, with over half ( 989) of these inside the reserve.

\section{Canyon habitat}

We conducted 28 transects (15 in the La Jolla Canyon and 13 in Scripps Canyon); 4 transects in Scripps Canyon were not included in the analysis because they were conducted in a habitat different from that observed in the La Jolla Canyon. Vermillion rockfish Sebastes miniatus and sheephead were the most commonly observed fishes in the canyons. Other fished species occasionally observed included, cabezon Scorpaenichthys marmoratus, brown rockfish Sebastes auriculatus, copper rockfish S. carnatus and other rockfish (Sebastes spp.) that were not easily identifiable in the videos. Statistical analyses compar-

Table 2. Sebastes miniatus (male and female) and Semicossyphus pulcher (male). Mean (SE) and range in relative abundances. Counts of fishes observed on transects were divided by transect length to yield standardized fish abundances. Probabilities (Mann-Whitney $U$-tests) are shown. Sample sizes: La Jolla Canyon 15, Scripps Canyon 9

\begin{tabular}{|lcccccc|}
\hline \multirow{2}{*}{ Area } & \multicolumn{3}{c}{ Sebastes miniatus } & \multicolumn{3}{c|}{ Semicossyphus pulcher } \\
& Mean & (SE) & Range & Mean & (SE) & Range \\
\hline La Jolla Canyon & 1.81 & $(0.709)$ & $0-6.88$ & 0.061 & $(0.0158)$ & $0-0.129$ \\
Scripps Canyon & 0.26 & $(0.171)$ & $0-0.90$ & 0.003 & $(0.0032)$ & $0-0.019$ \\
p-value & & 0.017 & & & 0.006 & \\
Power & & 0.85 & & & 0.99 & \\
\hline
\end{tabular}

Table 3. Comparisons of density estimates of harvested species in 1979 (Kobayashi 1979) and 2002 (present study). Only density estimates were provided for 1979, whereas $95 \%$ confidence limits are given for 2002 data. Ratio of mean 1979:2002 densities is also shown

\begin{tabular}{|c|c|c|c|c|}
\hline \multirow[t]{2}{*}{ Species } & \multirow{2}{*}{$\begin{array}{c}1979 \\
\text { Mean }\end{array}$} & \multicolumn{2}{|c|}{$-2002-$} & \multirow[t]{2}{*}{ 1979:2002 } \\
\hline & & Mean & $95 \% \mathrm{CL}$ & \\
\hline Panuliris interruptus & 0.40 & 0.047 & 0.032 & $\sim 8$ \\
\hline Haliotis corrugata & 0.24 & 0.003 & 0.002 & $\sim 93$ \\
\hline Haliotis fulgens ${ }^{\mathrm{a}}$ & 0.04 & 0 & & \\
\hline Haliotis fulgens ${ }^{\mathrm{b}}$ & 0.04 & 0.007 & 0.004 & $\sim 6$ \\
\hline Octopus sp. & 0.04 & 0.0006 & 0.0012 & $\sim 62$ \\
\hline Strongylocentrotus franciscanus & 0.12 & 0.855 & 0.299 & $\sim 0.14$ \\
\hline Paralabrax clathratus & 0.44 & 0.029 & 0.017 & $\sim 15$ \\
\hline Paralabrax nebulifer & 0 & 0.005 & 0.003 & \\
\hline Semicossyphus pulcher & 0 & 0.032 & 0.013 & \\
\hline Scorpaena guttata & 0.04 & 0.0006 & 0.0012 & $\sim 62$ \\
\hline
\end{tabular}

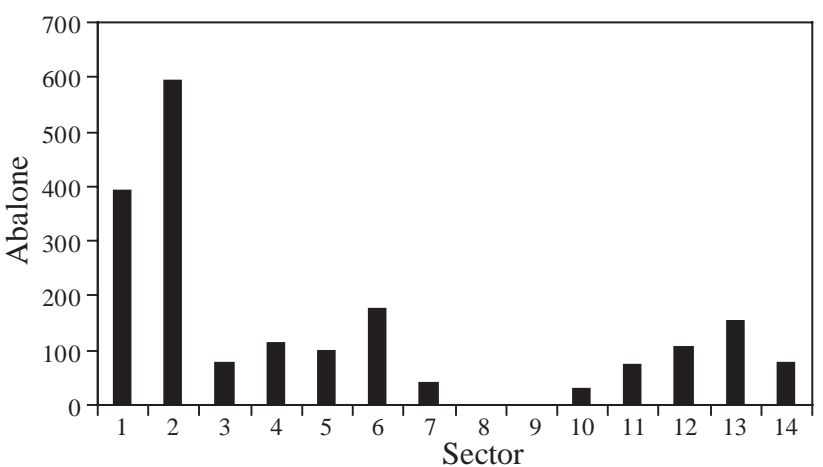

Fig. 7. Haliotis fulgens. Estimates of present population size for each $500 \mathrm{~m}$ section (sector) of coastline from $\mathrm{N}$ to $\mathrm{S}$ in La Jolla area. Sectors 1 and 2 are located within San DiegoLa Jolla Ecological Reserve

ing fish abundance among canyons were only possible for vermillion rockfish and sheephead, since all other species were observed too infrequently or were not entifiable with certainty.

The average transect length was $\sim 66 \mathrm{~m}$ (range 48 to $76 \mathrm{~m}$ ). The total number of individuals observed for each species was divided by the pathlength to yield a standardized estimate of relative abundance (fish $\mathrm{m}^{-1}$ ) for each species (Table 2). Relative abundances of both species were significantly greater for both species (Mann-Whitney $U$-tests; $p=0.017$ and $\mathrm{p}=0.006$ for vermillion rockfish and sheephead, respectively).

\section{Historical data}

Comparisons of density estimates from Kobayashi (1979) with those of the present study for populations of harvested species within the reserve are given in Table 3 . The estimates from Kobayashi (1979) are for the same kelp habitat as that sampled in the present study. Kobayashi (1979) also provided estimates of densities in the same boulder-reef habitat we surveyed for green abalone in 2002. Therefore, our estimates of green abalone densities in this habitat are directly comparable to his estimates in the boulder-reef habitat. Densities of green abalone were $0.04 \mathrm{~m}^{-2}$ in 1979 and $0.0072 \mathrm{~m}^{-2}$ (95\% confidence limit; 0.0040) in 2002 in the boulder-reef habitat. 
Table 4. Results of public survey presented by user group and for all participants pooled. Questions asked by interviewers are in the footnote (correct answers in bold)

\begin{tabular}{|c|c|c|c|c|c|c|}
\hline & $\begin{array}{l}\text { Interviews } \\
(\mathrm{N})\end{array}$ & $\begin{array}{c}\text { Awareness }{ }^{\mathrm{a}} \\
(\%)\end{array}$ & $\begin{array}{c}\text { Boundaries }^{\mathrm{b}} \\
(\%)\end{array}$ & $\begin{array}{c}\text { Correct } \\
\text { boundaries }^{\mathrm{c}}(\%)\end{array}$ & $\begin{array}{l}\text { Necessity }^{\mathrm{d}} \\
(\%)\end{array}$ & $\begin{array}{c}\text { Negative } \\
\text { consequences }^{\mathrm{e}}(\%)\end{array}$ \\
\hline Divers & 50 & 100 & 90 & 38 & 94 & 45 \\
\hline Fishers & 50 & 98 & 90 & 40 & 72 & 70 \\
\hline Kayakers & 32 & 91 & 76 & 31 & 94 & 62 \\
\hline Beach-goers & 50 & 60 & 60 & 6 & 100 & 42 \\
\hline Public & 50 & 70 & 63 & 18 & 94 & 49 \\
\hline Pooled & 232 & 83 & 79 & 33 & 90 & 54 \\
\hline \multicolumn{7}{|c|}{ aQ: 'Have you heard of the San Diego/La Jolla Ecological Reserve?' } \\
\hline \multicolumn{7}{|c|}{ bQ: (asked only of people who were aware of the Reserve): 'Do you know the boundaries of the Reserve?' } \\
\hline \multicolumn{7}{|c|}{$\begin{array}{l}\text { 'QQ: (asked only of people who claimed to know the boundaries): (1) 'Can you tell me how far north of the Cove the Reserve } \\
\text { extends?' Multiple choice: (a) South La Jolla Shores, (b) North La Jolla Shores, (c) } 100 \text { m south of Scripps Pier, (d) Torrey } \\
\text { Pines, (e) don't know. (2) 'Can you tell me how far offshore the Reserve extends? Multiple choice: (a) } 3 \text { miles, (b) } 2 \text { miles, } \\
\text { (c) } 1 \text { mile, (d) to a line extending north of the Cove, (e) don't know }\end{array}$} \\
\hline \multicolumn{7}{|c|}{ dQ: 'Do you think we need marine reserves?' Choices: yes, no, not sure (give reasons if yes or no) } \\
\hline
\end{tabular}

\section{Public survey}

A total of 232 participants were surveyed during the spring and summer of 2003. Some of the results of the survey are summarized in Tables 4 \& 5, other results not in Tables $4 \& 5$ are described below. Of the participants that believed there were negative consequences associated with marine reserves, 38\% were concerned about public access and use, 20\% were concerned about fishing becoming increasingly restricted, 19\% thought there might be serious economic effects, $7 \%$ were concerned that protected areas might have undesirable effects on coastal ecosystems, 3\% questioned the integrity of scientists investigating the reserves suggesting they had a 'hidden agenda', and $2 \%$ were concerned that there would not be sufficient enforcement for reserves to be effective. When asked what percent-

Table 5. Results of public survey presented for all reserve user groups (pooled only). Sources of information for people questioned (see footnote) who correctly knew the boundaries of the reserve

\begin{tabular}{|lc|}
\hline Information source $^{\mathrm{a}}$ & Response (\%) \\
\hline Word of mouth & 53 \\
Signs & 27 \\
Internet & 10 \\
Books, fliers or maps & 6 \\
Buoy markers & 2 \\
Other & 2 \\
aQ: 'Can you tell me how you learned about the boundaries \\
of the reserve?' Multiple choice: (a) word of mouth, \\
(b) signs, (c) internet, (d) other (specify if other) \\
\hline
\end{tabular}

age of state waters in California were currently protected (the correct answer at the time was $0.4 \%$; McArdle 1997), 50\% admitted they did not know, 20\% answered correctly $(<1 \%$ of state waters), and $30 \%$ responded with a larger percentage. Participants were also asked how much of the California coastline should be protected: $13 \%$ believed that the entire coastline should be protected, $21 \%$ said $50 \%, 20 \%$ said $20 \%$, $11 \%$ said $10 \%, 6 \%$ said $5 \%, 3 \%$ said $1 \%$, and $2 \%$ believed that no coastal areas should be protected; $24 \%$ did not know. Most fishers believed that 10 to $20 \%$ should be protected ( $57 \%$ of those that expressed an opinion).

\section{DISCUSSION}

The question of how large reserves must be to be effective is still unresolved (Halpern \& Warner 2003). Therefore, studies of reserve effectiveness over a range of sizes in a variety of climatic zones and habitats are needed (see Halpern 2003 for review). Study of the SDLJER is useful in this respect because it is one of the older reserves in California, it contains different habitats including many targeted species, and because historical survey data are available (Kobayashi 1979). Unfortunately, no baseline surveys were conducted prior to the establishment of the reserve to facilitate a BACI study, as is the case for many older reserves (see Halpern 2003). However, knowledge of the effectiveness of older reserves, in which long-term reserve effects have been established, is quite useful for the design of future reserves. We attempted to overcome 
the lack of baseline data to determine the effectiveness of the SDLJER using several approaches (e.g. Underwood 1994), most specifically by conducting comparisons among microhabitats that were determined quantitatively. We also attempted to overcome some of the shortcomings inherent to reserve studies (outlined in Willis et al. 2003) such as spatial confounding and sample replication. Historical data provided yet another important perspective on the effectiveness of the reserve because the trends of populations within and nearby the reserve attest to its effectiveness over time.

In general, the results of the inside/outside comparisons and our comparisons with historical data yielded 4 general conclusions: (1) the SDLJER appears to protect only a few harvested species, those that are sessile or highly residential; this suggests (enforcement issues aside) that the reserve is too small. (2) Comparisons with historical data indicate that most harvested species in the reserve, even some species for which reserve effects were observed, have declined seriously since 1979; this indicates that the magnitude of any reserve effect is inadequate to protect most species from natural and anthropogenic perturbations, further supporting the contention that the reserve is too small. (3) the reserve may function as an enhancive reserve for green abalone in the boulder-reef habitat, red urchins in the kelp habitat, and vermilion rockfish and sheephead in the canyon habitat, since large individuals of these species were observed in higher densities inside the reserve than outside, including the entire area off La Jolla. (4) Historical data are important in determining reserve effectiveness when baseline data are lacking because they provide an historical perspective with which to gauge inside/outside comparisons.

With regard to the sustainability of the reserve, its size is small relative to the home ranges of many species inhabiting the protected habitats. Therefore, the suite of species for which the reserve might be expected to effectively protect is small relative to the pool of species that are exploited in the area. The areas of kelp and boulder-reef habitat that are protected by the reserve are particularly small when compared to the same contiguous habitats located throughout the La Jolla area. The reserve protects only $\sim 0.8 \%$ of the kelp forest habitat and $\sim 11 \%$ of the boulder-reef habitat in the La Jolla area.

\section{Kelp habitat}

Inside/outside density comparisons revealed significantly higher densities of male and female sheephead, rock scallops and red urchins inside the reserve. Densities of legal-sized lobsters were nearly significantly greater inside the reserve when Bonferroni adjustment was not applied. Application of a multiple comparison method (TPM) similar to sequential Bonferroni adjustment, indicated a high probability of a reserve effect for red urchins, and the likelihood of a reserve effect also for rock scallops, for which the single-comparison p-value $(\sim 0.015)$ was highly significant.

Of the fishes, only male sheephead displayed size differences between the reserve habitat and similar habitat outside. The proportion of large males $(>50 \mathrm{~cm})$ was significantly greater inside the reserve. Male sheephead in this size category are at least 10 to $20 \mathrm{yr}$ old (Cowen 1990) and are rarely observed outside the reserve. Male sheephead are important predators of urchins and are therefore capable of indirectly effecting kelp densities through a trophic cascade (Tegner \& Dayton 1981). Therefore, the reserve provides important conservation protection for large male sheephead, and the trophic structure within the reserve probably reflects a more pristine condition than that outside.

There were also significant differences with regard to sizes of red urchins inside and outside the reserve. The large modal size of red urchins inside the reserve was significantly greater than that outside the reserve. The lower boundary of the $95 \%$ confidence interval for the large mode of red urchins inside the reserve was $96 \mathrm{~mm}$, while that for red urchins outside the reserve was $85 \mathrm{~mm}$, just $2 \mathrm{~mm}$ larger than legal harvesting size. The implication that this is a result of a release from fishing pressure is supported by the nearly identical size distributions and densities of purple urchins (not fished) inside and outside the reserve. A reserve effect for red urchins has also been observed in the San Juan Islands, Washington, where medium and large urchins made up a significantly greater proportion of the population in some marine reserves (Tuya et al. 2000). Ironically, it is unlikely that the population of red urchins inside the reserve is self-seeding given the long larval planktonic period of this species (Tegner \& Dayton 1977). Therefore, the reserve is probably not self-sustaining for red urchins even though the strongest protection was observed for this species.

The lack of trophic cascade observed within the reserve that has been observed in reserves of different systems (e.g. Sala et al. 1998) should be noted. Given the higher abundance of larger male sheephead, important predators of large red urchins (Cowen 1983), one would not expect to find higher densities and larger sizes of red urchins inside the reserve. This strongly suggests that anthropogenic pressure on red urchins is much stronger than natural predator pressure.

In summary, the results of inside/outside comparisons indicate that the reserve provides protection only for species that are strictly residential or sessile (red urchins, rock scallops and sheephead). Species such as kelp bass and barred sand bass whose ambits are 
much larger than the size of the kelp habitat in the reserve are not afforded protection. Unfortunately, the kelp habitat inside the reserve is not an optimal habitat for many other species of fishes (including many species of rockfish Sebastes spp.) whose ambits are small enough for the reserve to afford some protection. Therefore the reserve is of little value for these heavily exploited species.

Historical comparisons of densities in the kelp habitat inside and outside the reserve indicate alarming declines in many fished species inside the reserve: lobsters, green abalone, pink abalone, octopus, kelp bass and sculpin Scorpaena guttata whose mean densities have sharply declined (Table 3). Although the raw data from Kobayashi's (1979) study were not available for analysis, average densities for these species were so much lower in our study that it is obvious that the differences are important. In contrast to the declines observed for these species, the average density of red urchins is presently more than 7 times greater than in 1979.

A combination of factors is likely to be responsible for the declining trends in abalone and urchin abundance. The biggest environmental difference between 1979 and 2002 is the amount of kelp canopy. Prior to 1980, there was very little canopy in the reserve and throughout much of the northern La Jolla area (North \& Jones 1991). Heavy canopy did not develop in northern La Jolla and the reserve until the mid-1980s following the strong El Niño 1982/1983 event. The lack of kelp canopy during this period suggests foodlimitation of urchins and abalone, both of which feed on giant kelp. In fact, in 1979, purple urchins were not observed in the kelp habitat and red urchins were much less abundant, again reflecting vastly reduced food availability. The cause of the abalone decline is more complex. Green abalone, which were not observed in 2002 in the kelp habitat, were still relatively common in 1979 in the same habitat despite the limited food available at that time. While recreational divers have reported many cases of poaching in the reserve, green abalone populations throughout much of southern California (Moore et al. 2002) and in the reserve (R. McConnaghey pers. comm.) were decimated in the early 1980s by 'withering-foot syndrome', a parasite-induced disease. Therefore, a combination of poaching and disease has impacted abalone in this area, complicating tests of reserve effectiveness for these species.

Kelp bass are not protected by the reserve, and their populations have decreased since 1979 by a factor of $\sim 15$. Giant kelp is the primary adult and nursery habitat (Carr 1989) for kelp bass and one would therefore expect larger populations of kelp bass at present since there was much less kelp in 1979. Their decreased abundance suggests that fishing is probably the cause of decline in this species: the reserve is not likely to be effective for kelp bass because its boundary crosses the middle of the kelp forest, enabling movement across the boundary. Kelp bass exhibit some sitefidelity to a kelp bed (Hartney 1996, Lowe et al. 2003); however, they have been reported to range as far as $\sim 400 \mathrm{~m}$ (Quast 1968), an ambit far larger than the area of kelp forest inside the reserve. The reserve also offers little protection for sculpin, which have declined precipitously due to an active live-fish fishery (CDFG 2001). Sculpin can migrate kilometers to spawn (Hartmann 1987) and therefore cannot be protected by the small reserve, although a small reserve could offer important protection for a spawning aggregation.

\section{Boulder-reef habitat}

The reserve appears highly effective for green abalones within the boulder-reef habitat. Densities of green abalone were nearly 1 order of magnitude greater inside the reserve, and there was also a significantly greater density of larger individuals inside. Further, significantly greater densities of aggregations were observed within the reserve, and these aggregations were composed of larger individuals. Abalones are dioecious spawners and must aggregate within a few meters for successful fertilization of eggs; they are effectively sterile if not aggregated in groups of mixed sexes (Allee effect: e.g. Hobday et al. 2001). Therefore, the reserve appears to be protecting critically important spawning aggregations of green abalone. The estimates of green abalone numbers within the reserve indicate that well over half of the remaining population throughout the La Jolla area is protected by the reserve, even though the reserve only protects $\sim 11 \%$ of the green abalone habitat throughout the La Jolla area.

Despite the fact that the reserve appears to have protected green abalone prior to the closure of green abalone harvesting in 1998, historical comparisons of green abalone in boulder-reef habitat show a 6-fold reduction in density in the boulder-reef habitat since 1979. These differences, as previously discussed, are probably due to a combination of poaching, disease, and a decreasing larval supply due to dwindling stocks. Recreational divers have reported the disappearance of green abalone that they regularly visited in the reserve and the presence of scratch marks (indicating removal by an abalone iron) on the rocks where the green abalone formerly resided. During our surveys, we observed recently-lost abalone irons in the boulder-reef habitat indicating recent poaching activity. A very disturbing result of our study was the estimate of 
$<2000$ green abalone left throughout the La Jolla area. This is equivalent to $\sim 2$ to $3 \mathrm{~d}$ of take for divers from a single boat during the height of the green abalone fishery (J. Stewart pers. comm.). Despite the reduction in green abalone over the last $\sim 25 \mathrm{yr}$, it is fairly clear that the reserve has afforded some protection for green abalone, and this relict reserve population is an important potential source of future replenishment.

Our surveys in the boulder-reef habitat were specifically targeted at green abalone for logistical reasons. However, we commonly observed several very large $(>2 \mathrm{~kg}$ ) lobsters in the northeastern shallows (boulderreef habitat) of the reserve. Individuals of this size outside the reserve are very rarely observed; therefore, the reserve may be protecting some resident lobsters. Further evidence of this is the observation that lobster traps are still common at the western margin of the reserve late in the lobster season, when lobster traps have all but disappeared from the rest of San Diego, indicating there is spillover.

\section{Submarine-canyon habitat}

The canyon component of the reserve appears effective for male sheephead and vermillion rockfish. Both were observed in significantly higher abundances in the La Jolla branch of the La Jolla underwater canyon, located inside the reserve, than the Scripps branch of the canyon located outside. Unfortunately, no size data are available because the ROV was not equipped with lasers, but many individuals of both species appeared very large in the videos. Since both species are longlived, take several years to grow to sexual maturity, have home ranges smaller than the reserve, and spawn in groups, it is likely that the populations of these species within the reserve comprise important sources of juveniles. Further, they are probably the only populations of large individuals of these species remaining in the La Jolla area.

\section{Public survey}

Public awareness and support of marine reserves are essential components of reserve effectiveness. The results of our public survey suggest that while most people support reserves, a disturbing proportion were not aware of the SDLJER or its regulations and boundaries. Almost all who frequent the reserve such as divers and fishers were aware of its existence. However, only $60 \%$ of beach-goers, the group that is most likely to observe and report poaching, were aware of the reserve. Of greater concern is the limited knowledge of all groups regarding the boundaries of the reserve. Only $21 \%$ of all participants and $35 \%$ of fishers correctly knew the boundaries. This is of great concern since some or all of the buoys that mark the boundaries of the reserve frequently disappear or drift. Clearly, better public education is needed to enhance the enforcement of the reserve. Further evidence is the fact that one participant claimed he learned of the reserve by being arrested for poaching within it.

Although the survey showed that a majority of the public and $72 \%$ of fishers support the idea of marine reserves, many people interviewed believed that reserves are of limited practical value and some even believe they have negative consequences. Reasons for the latter supposition include limiting public access, putting too much of the ocean off-limits to fishers, economic loss, and even undesirable effects on coastal ecosystems. The results of the survey suggest that these concerns, whether real or perceived, must be addressed when future reserves are considered. The survey also revealed a disparity between how much of the California coastline is actually protected, how much people think is protected, and how much people think should be protected. About $50 \%$ of the participants thought they knew how much was protected, of these, more than half thought that at least $5 \%$ was protected. Currently, less than $1 \%$ of the coast is protected. More than $80 \%$ of respondents believed that at least $10 \%$ of the coastline should be protected suggesting there is public support for increased protection. These findings also indicate that more public education is needed to address the lack of accurate public knowledge regarding both the SDLJER and marine reserves in general.

\section{CONCLUSIONS}

For most harvested species, the SDLJER is clearly too small for the more general objective of marine reserves, that of the enhancement of marine resources via spillover of animals that have settled and grown in the reserve or the export of larvae sufficient to have a probability of enhancing the populations at large. Conservation reserves, however, simply protect a representative habitat and are not necessarily expected to enhance populations in general. For a conservation reserve to be successful, it needs to be sufficiently large to sustain the populations of interest. The SDLJER exhibits mixed success as a conservation reserve. It was established with only the specific goals of protecting the canyon walls and green abalone. It appears to have done that, and to have afforded protection for a few species of harvested fishes and invertebrates that are sessile or that have home ranges smaller than the size of the reserve. However, long-term declines in 
many of these species indicate that the reserve is not self-sustaining, except perhaps for vermilion rockfish and sheephead. The result is that given increasing levels of fishing pressure around the reserve, most exploited species are likely to further decrease within the reserve. Therefore, without further intervention in the form of increased fishing restrictions or additional local closures, the value of the SDLJER as a conservation reserve is questionable.

On a positive note, the reserve protects the most reproductively important remaining populations of green abalone and vermillion rockfish off La Jolla, and possibly in the San Diego County area. Both of these species depend on aggregations of adults, such as those only observed within the reserve, for successful reproduction. For these reasons, the reserve, despite its small size, may be important for the replenishment of these species in the future. However, given the rate at which green abalone have declined within the reserve, further intervention such as greater enforcement effort is probably necessary for their replenishment. The reserve may also be protecting reproductively important populations of large lobster and sheephead.

We cannot define the pristine (pre-human contact) system. So, we really cannot answer the question of 'where on the sliding baseline are we?' Perhaps, we are comparing 'slightly-overfished' to 'overfished' and considering the difference to be the amount of protection afforded by small marine reserves. As a conservation reserve, SDLJER appears to protect an important submarine-canyon habitat for vermillion rockfish and sheephead, and it has protected boulder-reef habitats with reproductively important populations of green abalone. However, the reserve is simply too small for most species to be self-sustaining. Further, it is questionable whether any reserve response will continue to be observed if fishing pressure continues to increase and enforcement is not strengthened.

Acknowledgements. We dedicate this paper to Connie Limbaugh, Wheeler North, Jim Stewart and Jay Quast, pioneer divers who worked to protect these resources long ago. We thank J. Stewart, R. McConnaghey, J. Quast, W. North, B. Kobayashi and R. Rosenblatt for discussions about the history of the establishment of the reserve. K. Whiteside, A. DeMent, E. Kisfaludy, M. Carter and N. Barger assisted us in the field. K. Whiteside, A. DeMent and N. Barger assisted with the public survey. We thank I. Tetrault for providing preliminary data on her recent study of the reserve. B. Rosenthal of Ocean Innovations (La Jolla) kindly loaned us his SeaBotix LBV-150 ROV. L. Deysher of Ocean Imaging (Solana Beach) provided the aerial images for the green abalone work. Comments by anonymous reviewers and $\mathrm{J}$. Quast were appreciated and greatly improved the final product. Support was provided by the Ralph M. Parson's Foundation, the Adelaide and Charles Link Foundation, the UCSD Civic Collaborative program, and California Sea Grant (RCZ-177).

\section{LITERATURE CITED}

Bohnsack J (1998) Application of marine reserve to reef fisheries management. Aust J Ecol 23:298-304

Carr MH (1989) Effects of macroalgal assemblages on the recruitment of temperate zone reef fishes. J Exp Mar Biol Ecol 126:59-76

CDFG (California Department of Fish \& Game) (2001) California's living marine resources: a status report. Publ. No. SG01-11. California Department of Fish \& Game, Resources Agency, University of California

Cowen RK (1983) The effect of sheephead (Semicossyphus pulcher) predation on red sea urchin (Strongylocentrotus franciscanus) populations: an experimental analysis. Oecologia 58:249-255

Cowen RK (1990) Sex change and life history patterns of the labrid Semicossyphus pulcher across an environmental gradient. Copeia 3:719-742

Dayton PK, Sala E, Tegner MJ, Thrush S (2000) Marine reserves: parks, baselines, and fishery enhancement. Bull Mar Sci 66:617-634

Efron B, Tibshirani RJ (1993) An introduction to the bootstrap. Monographs on statistics and applied probability No. 57. Chapman \& Hall, New York

Halpern BS (2003) The impact of marine reserves: do reserves work and does size matter? Ecol Appl 13(Suppl): S117-S137

Halpern BS, Warner RR (2003) Matching marine reserve design to reserve objectives. Proc R Soc Lond Ser B 270: 1871-1878

Hartmann AR (1987) Movement of scorpionfishes (Scorpaenidae: Sebastes and Scorpaena) in the Southern California Bight. Calif Dep Fish Game Fish Bull 73:68-79

Hartney (1996) Site fidelity and homing behavior of some kelp-bed fishes. J Fish Biol 49:1061-1069

Hobday AJ, Tegner MJ, Haaker PL (2001) Overexploitation of a broadcast spawning marine invertebrate: decline of the white abalone. Rev Fish Biol Fish 10:493-514

Holm S (1979) A simple sequentially rejective multiple test procedure. Scand J Stat 6:65-70

Kaufman L, Rousseeuw PJ (1990) Finding groups in data, an introduction to cluster analysis. John Wiley \& Sons, New York

Kobayashi BN (1979) California marine waters, areas of special biological significance reconnaissance survey report: San Diego-La Jolla Ecological Reserve, Water Quality Monitoring Report No. 79-1. California State Water Resources Control Board, Sacramento, CA

Kuhn GG (1984) Sea cliffs, beaches, and coastal valleys of San Diego County. University of California Press, Berkeley, CA

Lowe CG, Topping DT, Cartamil DP, Papastamatiou YP (2003) Movement patterns, home range, and habitat utilization of adult kelp bass Paralabrax clathratus in a temperate notake marine reserve. Mar Ecol Prog Ser 256:205-216

Manly BF (1991) Randomization and Monte Carlo methods in biology. Chapman \& Hall, London

McArdle DA (1997) California marine protected areas, Publ. No. T-039. California Sea Grant College System, University of California, La Jolla, CA

McClanahan TR (1999) Is there a future for coral reef parks in poor tropical countries? Coral Reefs 18:321-325

Moore JD, Finley CA, Friedman CS, Robbins TT (2002) Withering syndrome and restoration of southern California abalone populations. Calif Coop Ocean Fish Investig Rep 43:112-119

Neuhäuser M (2004) Testing whether any of the significant tests within a table are indeed significant. Oikos 106: $409-410$ 
North WJ, Jones LG (1991) The kelp beds of San Diego and Orange counties. MBC Applied Environmental Sciences, Costa Mesa, CA

Quast JC (1968) Observations on the food and biology of the kelp bass, Paralabrax clathratus with notes on its sportfishery at San Diego, California. Calif Dep Fish Game Fish Bull 139:81-108

Russ GR, Alcala AC (1996) Do marine reserve export adult fish biomass? Evidence from Apo Island, central Philippines. Mar Ecol Prog Ser 132:1-9

Sala E, Ribes M, Hereu B, Zabala M, Alvà V, Coma R, Garrabou J (1998) Temporal variability in abundance of the sea urchins Paracentrotus lividus and Arbacia lixula in the northwestern Mediterranean: comparison between a marine reserve and an unprotected area. Mar Ecol Prog Ser 168:135-145

Silverman BW (1986) Density estimation for statistics and data analysis. Monographs in statistics and applied probability. Chapman \& Hall, London

Tegner MJ, Dayton PK (1977) Sea urchin recruitment patterns and implications of commercial fishing. Science 196: 324-326

Tegner MJ, Dayton PK (1981) Population structure, recruitment and mortality of two sea urchins (Strongylocentrotus franciscanus and $S$. purpuratus) in a kelp forest. Mar Ecol Prog Ser 5:255-268

Editorial responsibility: Charles Birkeland (Contributing Editor), Honolulu, Hawaii, USA
Tremblay PC, Loder JW, Werner FE, Naimie CE, Page FH, Sinclair MM (1994) Drift of sea scallop larvae, Placopecten magellanicus, on Georges Bank: a model study of the roles of mean advection, larval behavior and larval drift. DeepSea Res II 41:7-49

Tutschulte TC, Connell JH (1988) Feeding behavior and algal food of three species of abalones (Haliotis) in southern California. Mar Ecol Prog Ser 49:57-64

Tuya FC, Soboil ML, Kido J (2000) An assessment of the effectiveness of marine protected areas in the San Juan Islands, Washington, USA. J Mar Res 57:1218-1226

Underwood AJ (1992) Beyond BACI: the detection of environmental impacts on populations in the real, but variable, world. J Exp Mar Biol Ecol 16:145-178

Underwood AJ (1994) On beyond BACI: sampling designs that might reliably detect environmental disturbances. Ecol Appl 4:3-15

Venables WN, Ripley BD (1999) Modern applied statistics with S-Plus, 3rd edn. Springer-Verlag, New York

Willis TJ, Millar RB, Babcock RC, Tolimieri N (2003) Burdens of evidence and the benefits of marine reserves: putting Descartes before des horse? Environ Conserv 30: 97-103

Zaykin DV, Zhivotovsky LA, Westfall PH (2002) Truncated product method for combining p-values. Genet Epidemiol 22:170-185

Submitted: June 1, 2004; Accepted: January 19, 2005

Proofs received from author(s): June 20, 2005 